\title{
The Burden of Infectious Diseases: A Trend Appraisal in Sub-Saharan Africa Regional Trade Blocs
}

\author{
Olufunmilayo Olayemi Jemiluyi ${ }^{1}$, Rebecca Folake Bank-Ola \\ ${ }^{1}$ Adeleke University, Ede, Nigeria \\ ${ }^{2}$ Adeleke University, Ede, Nigeria
}

\begin{tabular}{|c|c|}
\hline Article Info & Abstract \\
\hline $\begin{array}{l}\text { Article History: } \\
\text { Received:18 June } 2021 \\
\text { Revised: } 25 \text { August } 2021 \\
\text { Accepted:26 August } 2021\end{array}$ & $\begin{array}{l}\text { Purpose: The study aimed at presenting a comparative appraisal of the } \\
\text { trends of the two most prevalent infectious diseases bedeviling the } \\
\text { region: human immunodeficiency virus (HIV) and tuberculosis (TB). } \\
\text { Subject \& Methods: Data on fourteen ECOWAS member countries and } \\
\text { also fourteen member countries of the SADC bloc. This represents about } \\
93.3 \%\end{array}$ \\
\hline $\begin{array}{l}\text { Keywords: } \\
\text { Infectious Diseases, } \\
\text { Human Immunodeficiency } \\
\text { Virus (HIV), Tuberculosis } \\
\text { (TB), Sub-Saharan Africa, } \\
\text { ECOWAS, SADC }\end{array}$ & $\begin{array}{l}\text { respectively. Although the choice of sample size is determined largely by } \\
\text { the availability of data, the choices were carefully made to maximize } \\
\text { available observation. The data were sourced from World Development } \\
\text { Indicators online database published by the World Bank. We use two } \\
\text { measures of infectious diseases: the prevalence rate of human } \\
\text { immunodeficiency virus and the incidence of tuberculosis. } \\
\text { Results: The HIV prevalence rates and incidence of TB were uneven in }\end{array}$ \\
\hline $\begin{array}{l}\text { Paper Type : } \\
\text { Research Arti }\end{array}$ & $\begin{array}{l}\text { the two selected trade blocs. The magnitude and the severity of the } \\
\text { diseases varied. The burden of both diseases was higher for SADC and } \\
\text { lesser for ECOWAS. The average prevalence rate of HIV in the SADC }\end{array}$ \\
\hline $\begin{array}{l}\text { Correspondence Author } \\
\text { Olufunmilayo Jemiluyi } \\
\text { Email: } \\
\text { jemiluyi.olayemi@adelekeuniv } \\
\text { ersity.edu.ng }\end{array}$ & $\begin{array}{l}\text { bloc over the study period was } 600 \% \text { of the prevalence rate in ECOWAS } \\
\text { (SADC }=12.5 \% \text {, ECOWAS }=2.1 \% \text { ). Likewise, in the same period, the } \\
\text { average TB incidence per } 100,000 \text { people was } 578.8 \text { and } 181.7 \\
\text { respectively in the SADC and ECOWAS blocs. } \\
\text { Conclusions: The study finds that the magnitude and severity of the } \\
\text { diseases vary widely between the Economic Community of West Africa } \\
\text { States (ECOWAS) and the Southern Africa Development Community } \\
\text { (SADC) trade blocs. And, while concerted efforts at curbing the diseases } \\
\text { have yielded results, there is still much to be done in both blocs. }\end{array}$ \\
\hline
\end{tabular}

\section{Introduction}

The emergence of the Coronavirus Disease (COVID-19) and its diverse consequences for macroeconomic performance across the globe has once again shown that the issue of health and issue of health and in particular the burden of infectious diseases cannot be overemphasized (IHME, 2020; Lancet, 2020). Health policies and actions have remained at the epicenter of developmental plans since the turn of the $21^{\text {st }}$ century. This follows from the increasing recognition of the role played by health in achieving economic growth and sustainable development. Improved health status is both an end in itself and also a means of achieving economic development (Lehoux et al., 2018; UN-SDG, 2017; Bloom et al., 2015).

In the sub-Saharan Africa (hereafter SSA) region, the problem of poor health has remained a global concern. Even though health indicators in most developing regions are lagging behind the highly industrialized economies of Northern America and Europe, the statistics in SSA countries compare poorly with those of other developing regions despite the considerable evidence that the region has benefitted from health-targeted aids (Global Fund, 2014; Van de Maele, Evans and Tan-Torres, 2013). For instance, despite the global 
remarkable progress in tackling communicable diseases, HIV/AIDS, tuberculosis and malaria have continued to account for a larger proportion of disability in SSA than the world as a whole, accounting for $90 \%$ of all malaria deaths, more than $70 \%$ of all people living with HIV/AIDS and $26 \%$ of all tuberculosis cases (IHME, 2018; UNICEF, 2016; World Bank, Global Burden of Disease, 2013).

In addition to the disproportionate burden of malaria, HIV/AIDS, and tuberculosis, the region has continued to be plagued with diverse new and re-emerging infectious diseases such as cholera, Ebola virus disease (EVD), Lassa fever, meningococcal meningitis, monkeypox and poliomyelitis (Fenollar\& Mediannikov, 2018; Baingana \& Bos, 2006). Also, the region had its share of the COVID-19 scourge with marked adverse effects on the economies (WHO, 2021). The high burden of diseases coupled with a poor healthcare system had led to poor health capital characterized by high morbidity rate, high mortality rate, low life expectancy, poor maternal and child health indicators (World Development Indicators, 2020). Different episodic outbreaks of diseases across the SSA region in recent times have exemplified that the discussion on the macroeconomic effect of health in the region cannot be overemphasized. Besides the dreaded Ebola Virus Disease (EVD) outbreak in 2014 through 2016 in Guinea, Liberia, Sierra Leone, Nigeria, and Mali; Togo, Niger Republic, and Nigeria were likewise ravaged by meningococcal meningitis bacteria, with over 3000 deaths in the first quarter of 2017. In the same period, an outbreak of malaria with a total of almost 2 million cases was declared in Burundi and cases of Monkeypox were also recorded in Congo and Nigeria (WHO, 2017; CDC, 2017).

The welfare consequences of poor health are significant in SSA where about half of the world's poor lives and more than half of the population is engaged in subsistence agriculture and other low-income jobs for which physical strength has a payoff (World Bank, 2014, 2017; OECD-FAO, 2016; Orach, 2009). Given the foregoing, this paper appraises the trends of two prevalent infectious diseases: human immunodeficiency virus (hereafter HIV) and tuberculosis (hereafter TB) in two trade blocs of the SSA region from 1995 to 2018. Although the trends of infectious diseases had been investigated in SSA, most of the studies have focused on HIV, with scanty evidence on other infectious diseases such as TB. Moreover, few studies had been carried out at the aggregate level. Thus, in addition to HIV, this study also appraises the trend of TB and focuses on the regional trade blocs rather than an aggregated analysis of the region, as the burden of the diseases varies widely among the member countries of the trade blocs. Moreover, this is done to bring together members of the same regional blocs which tend to share similarities in socioeconomic structure and geographical location, which is a key determinant in the prevalence of infectious diseases which constitute an integral part of this study. Also, this is particularly important to provide clarity in the assessment and for ease of understanding of discussions and for the purpose of comparison.

\section{Materials and Methods}

For the stated objective of this study, data on fourteen ECOWAS member countries and also the fourteen-member countries of the SADC bloc were collected. This represents about 93.3\% and $87.5 \%$ membership of the ECOWAS and SADC blocs respectively. Although the 
choice of sample size is determined largely by the availability of data, the choices were carefully made to maximize available observation. The data were sourced from World Development Indicators online database published by the World Bank. We use two measures of infectious diseases: the prevalence rate of human immunodeficiency virus and the incidence of tuberculosis.

The analysis involves the use of uni-variate (individual-variable) graphical representation involving the use of charts to depict the trends of changes in the variables over the study period and across the SSA regional trade blocs. Furthermore, we make a comparison between the trade blocs, as well as with other regions with similar structures. Also, rather than singly examining the trend over the study period, we adopt a five years analysis to give a clearer and better understanding of the trends over the study period.

\section{Result \& Discussion}

\section{Trends of HIV and Tuberculosis in ECOWAS member countries}

The HIV prevalence rate in the member states of ECOWAS is presented in Figure 1. The trend reveals that at the onset of the scourge when data began to be made available, HIV prevalence rate was high and witnessed noticeable increases in all the ECOWAS countries, with the rate being as high as 3.6\% and 5.1\% in Burkina Faso and Cote d'Ivoire respectively in 1995, while in the same period, it was $2.6 \%$ in Ghana, $2.9 \%$ in Nigeria and 3.2\% in Togo. Between 1995 and 2000, the disease had a surge in most of the countries, with the prevalence rate peaking at a high of $5.6 \%$ in Cote d'Ivoire; $4.8 \%$ and $3.9 \%$ in Togo and Nigeria respectively. In that period (1995-2000), Sierra Leone had the highest growth rate of $350 \%$, moving from the prevalence rate of $0.2 \%$ to $0.9 \%$. Guinea-Bissau ranked second followed by Gambia with both countries having a growth rate of $200 \%$ and $183 \%$ respectively. It is interesting to note that the three countries with the highest growth rate between 1995 and 2000 were having the lowest prevalence rate in the regional bloc in 1995, below $1 \%$.

As depicted in Figure 2, in comparison with the global average and averages in other similar regions, the average HIV prevalence rate in the SSA region and ECOWAS bloc were relatively higher, with the SSA regional average being about $800 \%$ higher than the global average in most of the period of analysis. Although the average prevalence rate in the ECOWAS bloc fell below the SSA regional, average in all the periods, it was similarly high, being about $300 \%$ higher than the global average in most of the periods. 


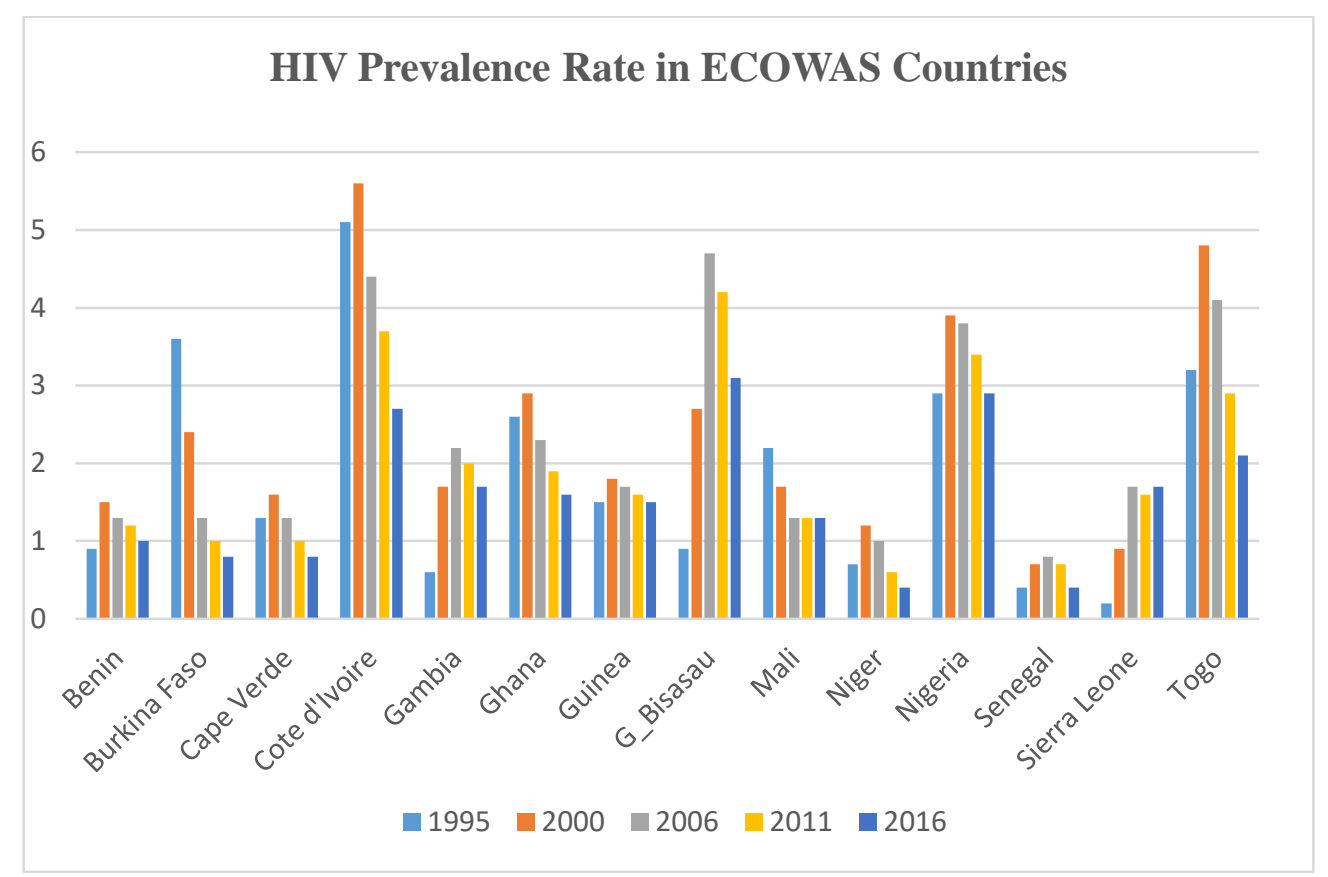

Figure 1: HIV Prevalence Rate in ECOWAS Countries

Source: Author's Construct based on WDI Data 1995-2016

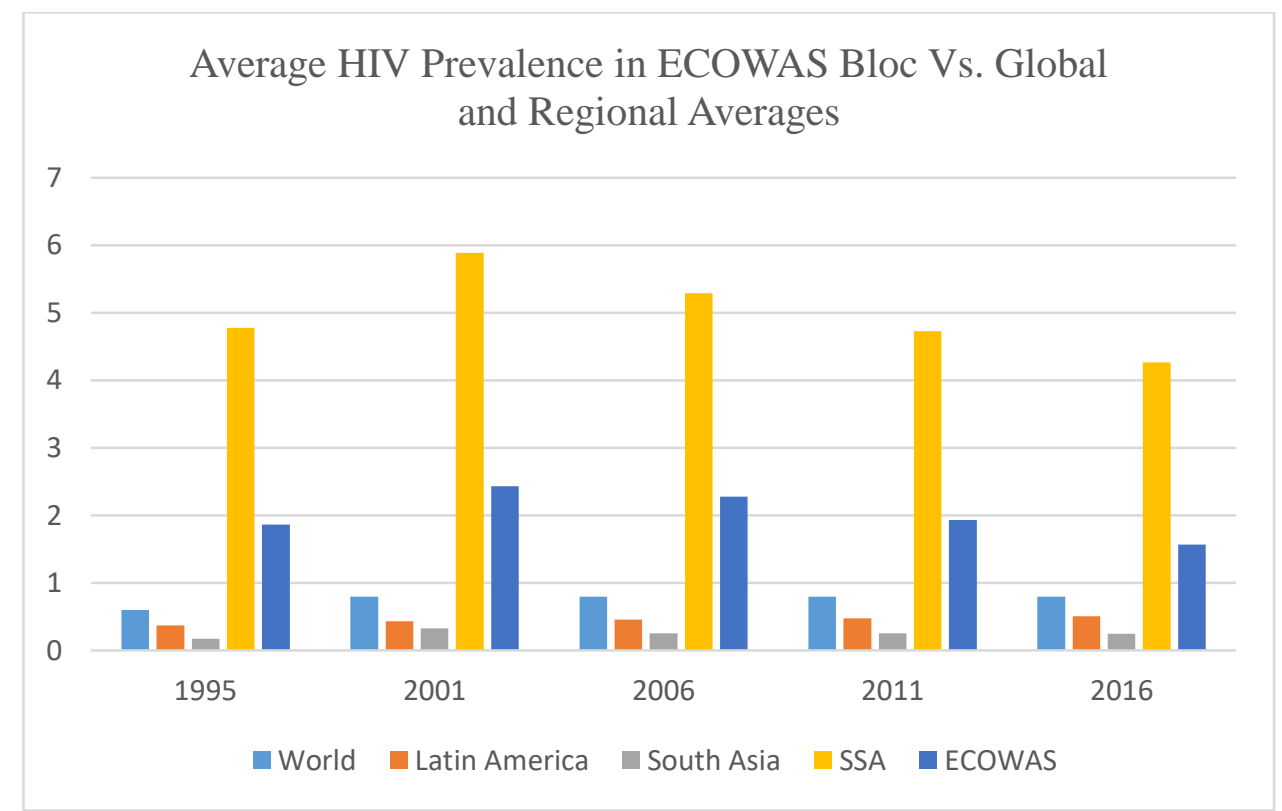

Figure 2: Average HIV Prevalence Rate in ECOWAS Vs. Global and Regional Averages Source: Author's Construct based on WDI Data 1995-2016

While the global average HIV prevalence rate over the study period was $0.8 \%$, it was $5.2 \%$ in SSA and $2.1 \%$ in the ECOWAS bloc. In the same vein, the average prevalence rate of HIV in the SSA and ECOWAS bloc exceeded the averages in Latin America $(0.45 \%)$ and South Asia $(0.27 \%) .{ }^{1}$ Specifically, the SSA average was about $2000 \%$ of the average in South Asia and $1200 \%$ of Latin America's. The relatively higher HIV prevalence rate in the SSA

\footnotetext{
${ }^{1}$ Data on HIV prevalence rate is not available for the East Asia region 
region affirms the conclusion that the region is a significant contributor to the global burden of the HIV/AIDS scourge.

Overall, in the ECOWAS sub-region, the HIV prevalence rate trended downward since 2000 , falling below $1 \%$ in 2016 in about $29 \%$ of the countries ${ }^{2}$ and lesser than $2 \%$ in about $72 \%$ of the countries. Except in Gambia, Guinea-Bissau, Nigeria, Sierra Leone, and Togo, the regional bloc has recorded progress in achieving the global health goal of eradicating the HIV scourge, with the average prevalence rate in the sub-region declining from a peak of $2.4 \%$ in 2000 to $1.6 \%$ in 2016 , which is far below the average of $4.3 \%$ for the whole SSA region. The remarkable progress made in curtailing the spread of the virus in the ECOWAS bloc is however not unrelated to both the international and national efforts geared towards achieving the Millennium Development Goal (MDGs) of combatting HIV/AIDS and other diseases by 2015. This was largely supported by laudable efforts of national governments, the development community, and foreign aids from governments of developed economies and multilateral agencies (UNAIDS, 2018). ${ }^{3}$

Conclusively, while Nigeria in 2016 had the highest HIV prevalence rate of $2.9 \%$ in the ECOWAS bloc, ranking second to South Africa in the global burden of HIV/AIDS, the prevalence rate was as low as $0.4 \%$ in Niger and Senegal; and $0.8 \%$ in Burkina Faso and Cape Verde and $1 \%$ in Benin Republic. There had also been tangible progress even in countries with high prevalence rates in 1995. For instance, over the last two decades spanning from 1995 to 2016, the rate has fallen from 5.1 in Cote d'Ivoire to $2.7 \%$ and from $3.2 \%$ to $2.1 \%$ in Togo.

\section{Tuberculosis}

The incidence of TB in the ECOWAS bloc during the study period is depicted in Figure 3. Similarly, like the burden of HIV, the incidence of TB was very high in most member countries of the ECOWAS and varied in trends and magnitudes. While it rose in some countries from the start of the study period, it was declining in some in the same period. For instance, there were consistent declines in Benin, Burkina Faso, Cape Verde, Ghana, Guinea, Mali, Niger and Togo from the early periods of the study. In the same period, it was rising in Cote d'Ivoire, Gambia, Guinea-Bissau, Nigeria, and Sierra Leone, while it was fluctuating in Senegal. The increasing trend of TB was particularly persistent lasting a decade in Gambia, over a decade in Nigeria and Sierra Leone; and about two decades in Guinea-Bissau.

Also, the observed variations in the magnitude of TB in the ECOWAS bloc were likewise significant. For instance, while the incidence per 100,000 people at the start period was 51, 80 and 82 in Togo, Burkina and Mali in 1995, it was as high as 379, 285, 282 and 273 in Cote d'Ivoire, Nigeria, Sierra Leone and Guinea-Bissau respectively in the same period. Thus, at the start period, the incidence of TB was highest in Cote d'Ivoire (379/100,000 people)

\footnotetext{
${ }^{2}$ Comprising of Burkina Faso, Cape Verde, Niger Republic and Senegal

${ }^{3}$ Although HIV/AIDS prevention and control have been largely donor-driven in the sub-region through expertise and financial assistance from various HIV/AIDS global associations such as the Joint United Nations Program on HIV/AIDS (UNAIDS), International AIDS Society (IAS), President Emergency Plan for AID Relief (PEPFAR), International Partnership Against AIDS in Africa (IPAA),United Nations etc., governments in the sub-region are also complementing the effort through national programs such as the Nigeria's National Action Committee on AIDS (NACA), Sierra Leone's National HIV/AIDS Secretariat, as well as National AIDS Control Committee in Burkina Faso, Cameroon and Togo
}

\section{8}

Copyright (C) 2020-2021, Journal of Scientific Research in Medical and Biological Sciences (JSRMBS), Under the license CC BY- 4.0 
and least in Togo $(51 / 100,000)$. The trend of TB incidence fell in most member countries of the ECOWAS bloc particularly among the low-incident countries such as Benin, Burkina Faso, Cape Verde, Mali and Togo. For example, by 2016, TB incidence per 100,000 people had fallen to 59, 51, 56 and 46 in Benin, Burkina Faso, Mali and Togo respectively. Among the highincident countries (above 200/100,000 people) including Cote d'Ivoire, Ghana, Guinea, Guinea-Bissau, Niger, Nigeria and Sierra Leone, remarkable progress had also been made in Cote d'Ivoire, Ghana, Guinea and Niger. For instance, in Cote d'Ivoire, TB incidence fell from $379 / 100,000$ in 1995 to $137 / 100,000$ and from $271 / 100,000$ in Niger to $93 / 100,000$. Contrariwise, it rose from 282/100,000 to 301/100,000 in Sierra Leone and from 273/100,000 to $374 / 100,000$ in Guinea- Bissau. Even though the trend had been declining in Nigeria, the rate had been slow, thus the incidence remained very high at 219/100,000 in 2016.

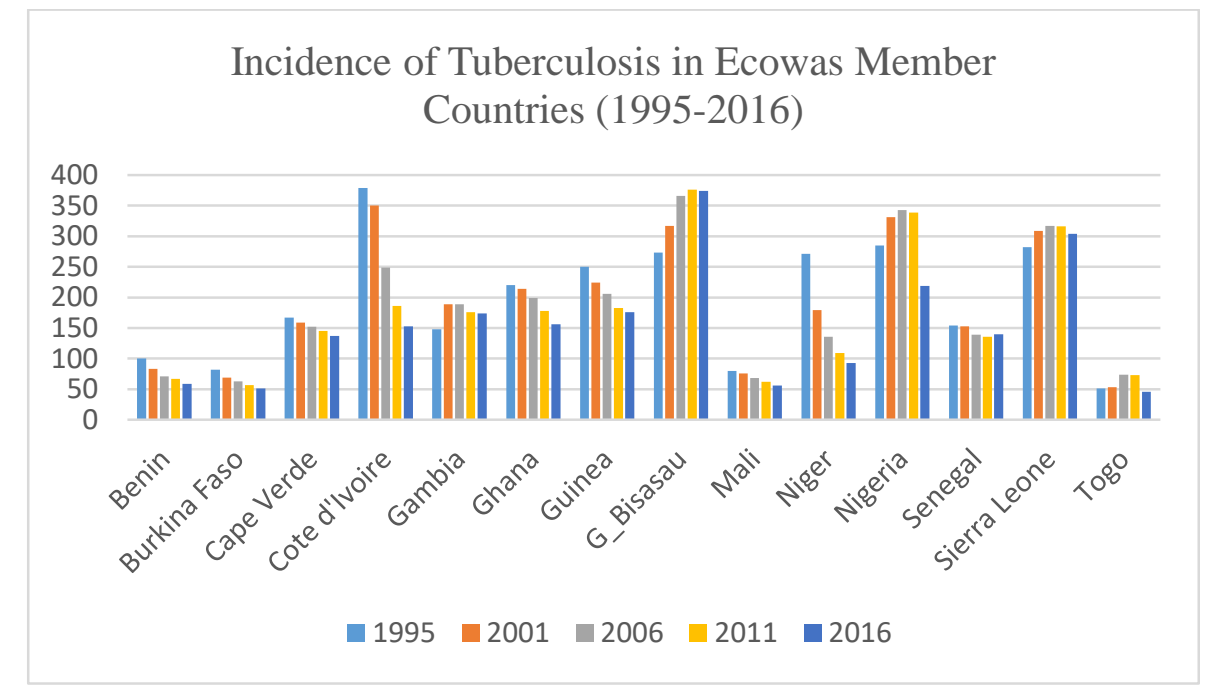

Figure 3: Incidence of Tuberculosis in ECOWAS Countries

Source: Author's Construct based on WDI Data 1995-2016

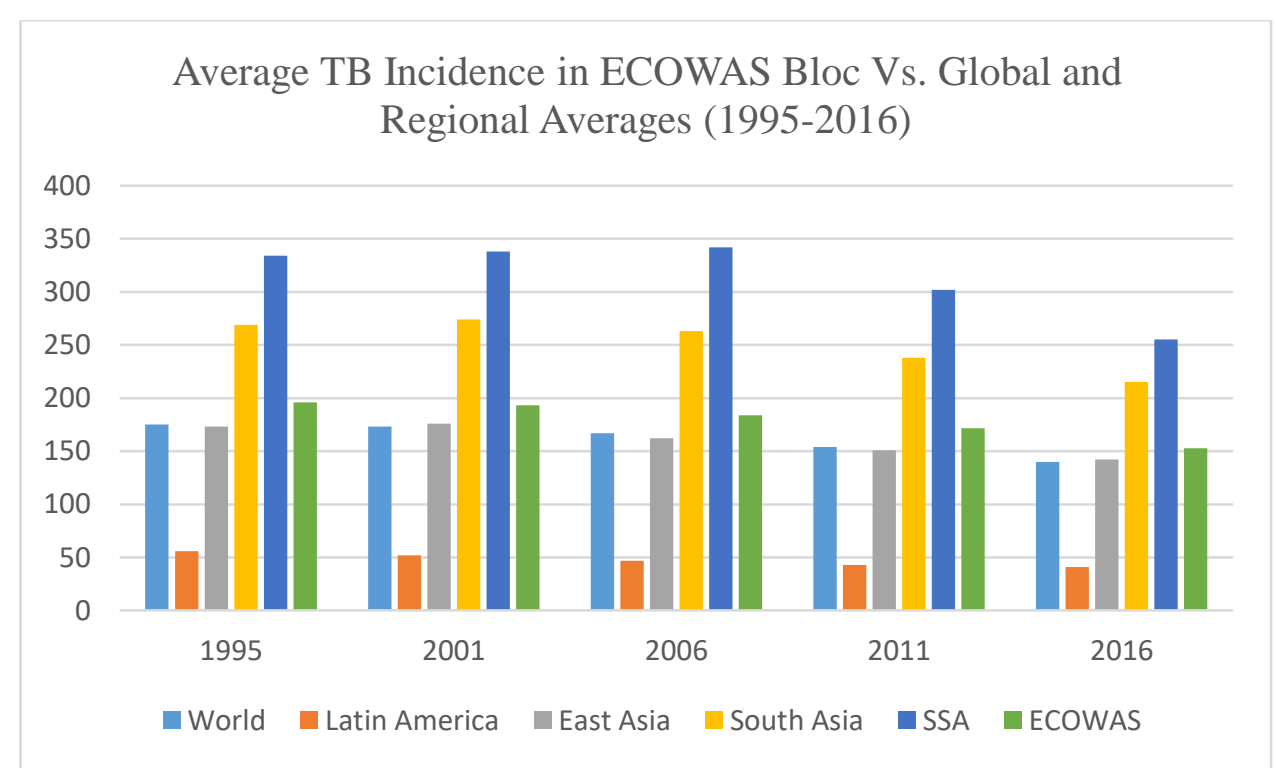

Figure 4: Average TB Incidence in ECOWAS Vs. Global and Regional Averages Source: Author's Construct based on WDI Data 1995-2016 
In sum, although there had been significant declines in the incidence of TB in some of the ECOWAS member countries, the incidence remained high in the ECOWAS bloc. Over the entire study period, Cote d'Ivoire had the highest rate of decline, falling from an incidence rate of 379/100, 000 people in 1995 to 153 in 2016 (losing 226), followed by Niger and Guinea, declining from 271 and 250 in 1995 to $93 / 100,000$ and 176/100, 000 people respectively in 2016. Togo had both the least incidence and the least decline rate of TB, falling from $51 / 100,000$ in 1995 to $46 / 100,000$ in 2016. It was only in Guinea-Bissau and Sierra Leone that the incidence rate at the end of the study period was higher than it was at the start period. Both countries had an increase of 101/100,000 and 22/100,000 people respectively between 1995 and 2016, ranking first and second country with the highest incidence of TB in the ECOWAS bloc.

In comparison with the prevalence of HIV, the trends of both diseases shared significant similarities (see Figure 1). The observed similarities in trends are not unlikely related to the coinfection that exists between both diseases (Oxlade and Murray, 2012). While there were exceptions, TB and HIV had similar trends in size and patterns in most of the selected countries. Prominent among the observed similarities was the case of Cote d'Ivoire. In Cote d'Ivoire, the prevalence of HIV and incidence of TB shared definite similarities in magnitude and their respective decline rates. While they were both high at the start period of the study, having the highest burden of the diseases in the bloc (5.1\% HIV prevalence and 379/100,000 people TB incidence), they both fell consistently having the highest decline in TB incidence and second highest in HIV prevalence.

Likewise, some other countries with high HIV prevalence also had a high incidence of $\mathrm{TB}$, with similarities in trends of increases or declines. Examples of such countries include Guinea-Bissau and Nigeria. HIV prevalence rates and the incidence of TB in both countries trended upwardly in most of the study period, persisting for a decade in the latter and over a decade in the former. At the end of the study period, HIV prevalence and TB incidence stood high in Guinea-Bissau and Nigeria, with both countries respectively ranking first and second highest in HIV prevalence and first and third in TB incidence respectively.

On the other hand, cases of divergent trends in both diseases include Togo, Burkina Faso, Sierra Leone and Niger. In Burkina Faso for instance, though it had since been falling, HIV prevalence was particularly high at the beginning of the study period ranking second in the bloc, however, the incidence of TB in the same period was low ranking twelfth among the fourteen selected ECOWAS countries. Also, in Togo, while HIV prevalence ranked among the highest in the bloc, peaking at $4.8 \%$ in 2000 and stood at a high of 2.6 in 2016, ranking third in the burden of HIV, TB incidence had been low having the lowest incidence in the region 51/100,000 in 1995 and 46/100,000 in 2016.

In comparison with the global trend and the trends in similar regions, Figure 4 shows that the incidence of tuberculosis was higher in both the SSA region and ECOWAS trade bloc than the global averages as well as the averages in similar regions such as Latin America, South Asia and East Asia. This is not surprising in that the burden of co-infection (HIV/AIDS) was similarly higher than all the regions investigated in this study. In all, the SSA region had the 
highest average incidence of TB $(314.6 / 100,000)^{4}$ followed by South Asia $(250.2 / 100,000)$. This indicates that the burden of TB in South Asia was higher than the ECOWAS trade bloc during the investigated period ${ }^{5}$. This is quite intriguing in that the South Asia region had the least prevalence rate of HIV during the study period. This further corroborates the stance that the relationship between the burdens of both diseases does not always indicate evidence of coinfection. This might also be lending support to the assertion that in recent times, TB poses greater challenges to global health than HIV, constituting the most common cause of infectious disease death globally (CDC, 2019; Basnyat, Caws and Udwadia, 2018). During the study period, the incidence of TB is least in Latin America with an average of 46.1/100,000.

In particular, based on available data, Latin American countries constitute one of the major TB-low incidence countries with less than 10/100,000 incidence rates. ${ }^{6}$ And despite the low incidence, TB represents a major health priority in the region with top-geared national and sub-national efforts towards achieving the Pan America Health Organization (PAHO) goal of eliminating TB with less than 1/1,000,000 incidence rate.

\section{Trends of Infectious Diseases in SADC Member Countries}

\section{HIV}

Based on available data, the burden of the HIV and AIDS epidemic was higher for the SADC than any other regional bloc in the SSA region and the world at large (WDI, 2018). It is the high prevalence rate of the disease in the SADC region that makes SSA the region with the highest prevalence rate and burden of HIV and AIDS respectively. The concerted effort by national governments and development partners aimed at curbing the spread of the disease had not yielded many results in the Southern Africa countries. Despite the remarkable progress achieved in the SSA region, the prevalence rate of the HIV scourge remained particularly high in the SADC bloc with $70 \%$ of the member countries having prevalence rates higher than $10 \%$.

From Figure 5, declines in the rates of adult HIV prevalence in the southern African countries during the study period compared relatively low to other trade blocs in the region. For instance, unlike the ECOWAS bloc where HIV prevalence rates in 2016 were lower than it was in 1995 in about $86 \%$ of the countries, about $71 \%$ of the SADC member states had prevalence rates higher than it was in 1995. The HIV prevalence rates were particularly high in Lesotho, Namibia, Mozambique, South Africa and Swaziland with growth rates of $117.4 \%$, $51.6 \%, 200 \%, 43.9 \%$ and $139.2 \%$ respectively over the study period. With an initial low

\footnotetext{
${ }^{4}$ This represents about $700 \%$ of the cases in Latin America and about $200 \%$ of the global record and East Asia's.

${ }^{5}$ In particular, TB has remained one of the major public health concerns in the South Asia region with significant burden of the disease in Bangladesh, China, India, Indonesia, Myanmar and Thailand. In terms of TB incidence, the South Asia region accounts for about $40 \%$ of the global burden of TB, with about half a million deaths annually.

However, with the adoption of active TB surveillance network and expanded high-quality TB services in most of the countries, the region has made tangible progress in case detection and treatment success rates, thereby curtailing the menace of the disease.

${ }^{6}$ Relative hypoxia, lower humidity or increased ultraviolet light in the region's mountainous terrain had been identified as possible causes for the low TB incidence (see Pelly, Moore, Gilman and Evans, 2004) 
prevalence rate in Mauritius in 1995, it had since witnessed a gradual increase, rising from $0.3 \%$ in 1995 to about $1 \%$ in 2016.

However, while the HIV prevalence rate remained persistently high in most of the SADC countries there were considerable improvements in some. For instance, peaking at a high of $25.3 \%$ in 1995, the HIV prevalence rate in Zimbabwe had continued to witness a consistent decline, declining to $18.1 \%$ in 2005 and fell further to $13.5 \%$ in 2016. Likewise, over the decades, HIV prevalence rates had been experiencing persistent fall in Zambia but at slower rates. While the prevalence rate was $15.6 \%$ in 1995, it fell to $13.8 \%$ and $12.4 \%$ in 2005 and 2015 respectively. Also, in the Democratic Republic of Congo, the prevalence rate declined from $1.8 \%$ in 1995 to $0.7 \%$ in 2016 . Nevertheless, much success has not been recorded in South Africa, Swaziland, Lesotho and Botswana as the prevalence rate of HIV remained at highs at $18.9 \%, 27.2 \%, 25 \%$ and $21.9 \%$ respectively in $2016^{7}$.

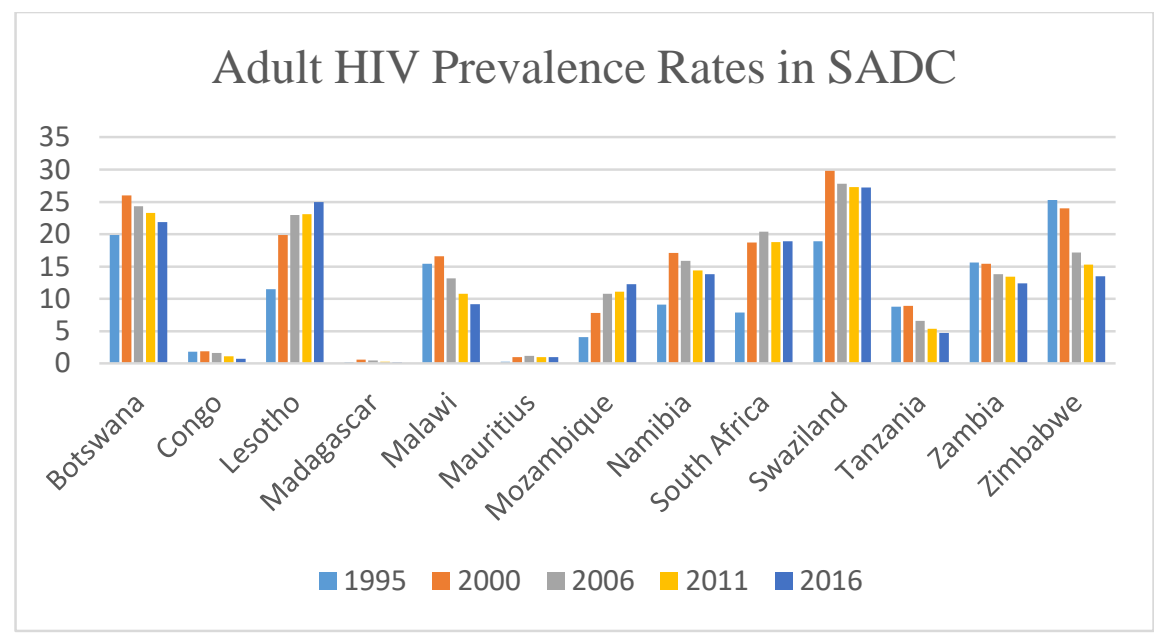

Figure 5: Adult HIV Prevalence Rate in SADC Member States

Source: Author's Construct based on WDI Data 1995-2016

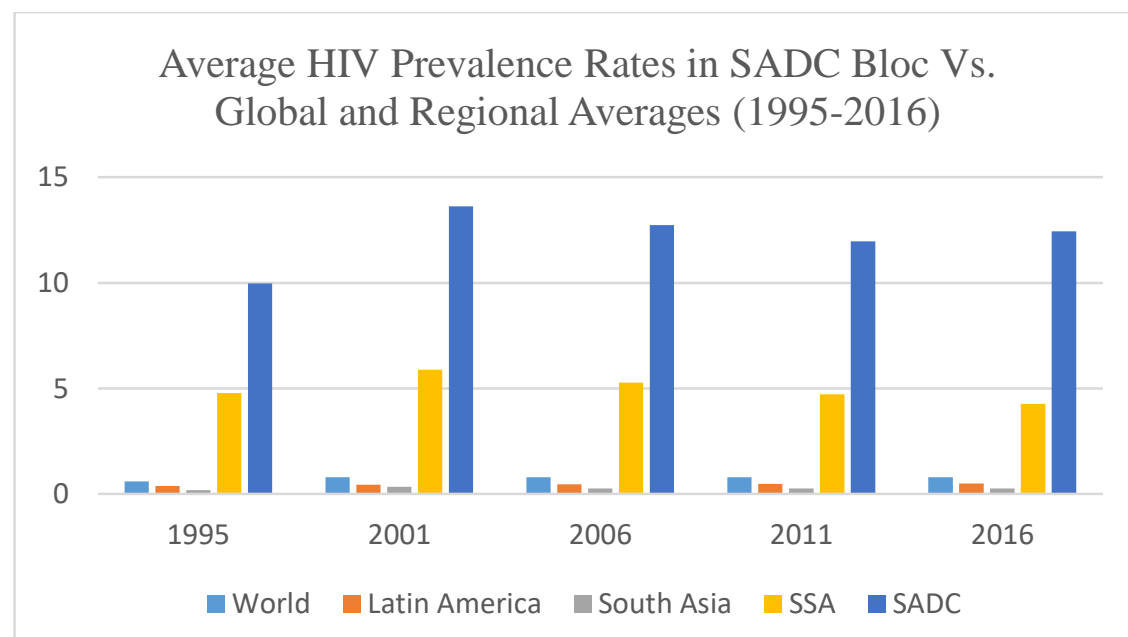

Figure 5: Average HIV Prevalence Rates in SADC Bloc Vs. Global and Regional Averages Source: Author's Construct based on WDI Data 1995-2016

\footnotetext{
${ }^{7}$ In fact, except in Angola, Congo, Madagascar and Mauritius, average HIV prevalence rate in other investigated southern Africa states exceeded the total regional average for SSA, being as high as 27.3\%, 23.9, $21 \%$ and $18.03 \%$ in Swaziland, Botswana, Lesotho and South Africa respectively. 
Figure 6 makes a comparison among SADC trade bloc, SSA and other similar regions. The analysis reveals the high density of the disease relative to other investigated regions. Of all the blocs in the SSA region, only in SADC is the average HIV prevalence rate higher than the total regional average. While the average HIV prevalence rate in SADC over the study period was $12.4 \%^{8}$, the regional average for SSA was $5.2 \%$ in the same period. Despite the heavy investment in antiretroviral therapies made by the Southern Africa governments ${ }^{910}$, much success has not been recorded in curtailing the scourge of the disease. This in particular has been hinged on some causal factors including high prevalence of risky sexual behaviors, rapid urbanization, risky culture such as genital and systemic inflammation, immigration, etc. (Avert, 2017; Vermund, Sheldon and Sidat, 2015; Muula, 2008).

\section{Tuberculosis}

The trend of TB incidence in the SADC bloc was very much similar to that of HIV prevalence rates in most of the selected member countries. It was similarly high in the high HIV-prevalent countries. Like the HIV prevalence rates, it trended upwardly in most of the periods. While it was not completely true in all the countries, the high burden of TB in the bloc was not unconnected with the high prevalence rate of HIV in the sub-region. Among countries sharing similar trends of TB incidence and HIV prevalence in the SADC bloc during the study period were Botswana, Lesotho, Mozambique, Namibia, Swaziland and Zambia.

At the start period of the study in 1995 , TB incidence per 100,000 people was particularly high standing at a high of 863, 847, 601, 479 and 471 in Botswana, Zambia, Namibia, Lesotho, Mozambique and Tanzania respectively. In the same period, it was 377 and 302 respectively in South Africa and Swaziland, while it was as low as 26 in Mauritius. It afterward declined in some of the countries while consistently rising in others. For example, in the period between 1995 and 2001, TB incidence witnessed a decline of $14.6 \%, 14.1 \%$ and $7.7 \%$ in Madagascar, Zambia and Mauritius respectively, while it rose as high as $153.6 \%, 30.2 \%$, 20.6\%, 86.4\% and 43.5\% in Swaziland, Lesotho, South Africa, Namibia and Zimbabwe respectively.

The trends of TB in Swaziland and South Africa were significantly similar to that of the HIV prevalence rate, in that in the same period, the latter increases respectively by $151.9 \%$ and $53.7 \%$ in both countries. Although the magnitude of HIV in Madagascar was relatively low in that period, it, however, had a growth rate of $200 \%$ (increasing from $0.2 \%$ to $0.6 \%$ ). The growth rates were also high in Namibia and Mozambique at $91.2 \%$ and $109.8 \%$ respectively.

\footnotetext{
${ }^{8}$ This represents over $200 \%$ of the average in SSA, and $1600 \%, 2800 \%$ and $4600 \%$ of the global, Latin America and South Asia averages respectively.

${ }^{9}$ South Africa has the world largest antiretroviral programme. Similarly, most of the southern Africa countries run efficient antiretroviral therapies, particularly the use of multiple drugs known as highly active antiretroviral therapy (HAART). The HAART mitigates the burden of HIV in an infected person while helping in maintaining the functionality of the immune system and prevent opportunistic infections that often lead to death (Vermund et al., 2015; AVERT, 2018)

${ }^{10}$ Also, southern Africa has been highlighted as the region with highest intervention priority by global efforts such as WHO, the United Nations Programme on HIV/AIDS (UNAIDS), the President's Emergency Plan for AIDS Relief (PEPFAR) and the Global Fund to Fight AIDS, Tuberculosis and Malaria (AVERT, 2018) 
Intriguing is the case of Mauritius who had a growth rate of $266.7 \%$ in HIV prevalence (from $0.3 \%$ to $1.1 \%$ ) and $7.7 \%$ decline in $\mathrm{TB}$ in the same period. Therefore, it was not in all countries, and periods in the SADC bloc was a high burden of TB evidence of co-infection with HIV.

The comparative analysis of the trends of incidence of TB with the global average and those of similar regions as depicted in Figure 8 shows that the trend is not different from that of the HIV prevalence rate. In the same vein as the HIV prevalence rate, the average incidence of TB was higher in the SADC trade bloc than SSA regional average and exceedingly higher than the global average and the averages in Latin America and South Asia. In reference to the selected similar regions, with an average TB incidence of 578.7/100,000 over the study period, the SADC bloc bears a disproportionate burden of the TB disease having an average incidence that was over $1200 \%$ of Latin America's and over $400 \%$ of East Asia's. Despite the high burden of TB in South Asia relative to the global average and those of Latin America and East Asia, the SADC's average $(578.7 / 100,000)$ during the study period was over $200 \%$ of the average in South Asia (250.2/100,000).

In the same vein, with a similarly high burden of the disease in EAC $(271.8 / 100,000)$ and ECCAS $(347.1 / 100,000)$ blocs, the incidence of TB in the SADC bloc exceeded all the trade blocs in SSA as well as the total average in the sub-region (314.6/100,000). There was an observable surge in 2001 and 2006, rising from an average of 463.8 in 1995 to 648.7 and 688.8 respectively. The observed surge might not be unrelated to the co-infection of the disease with HIV/AIDS whose prevalence rate was coincidentally high in the bloc in the same period.

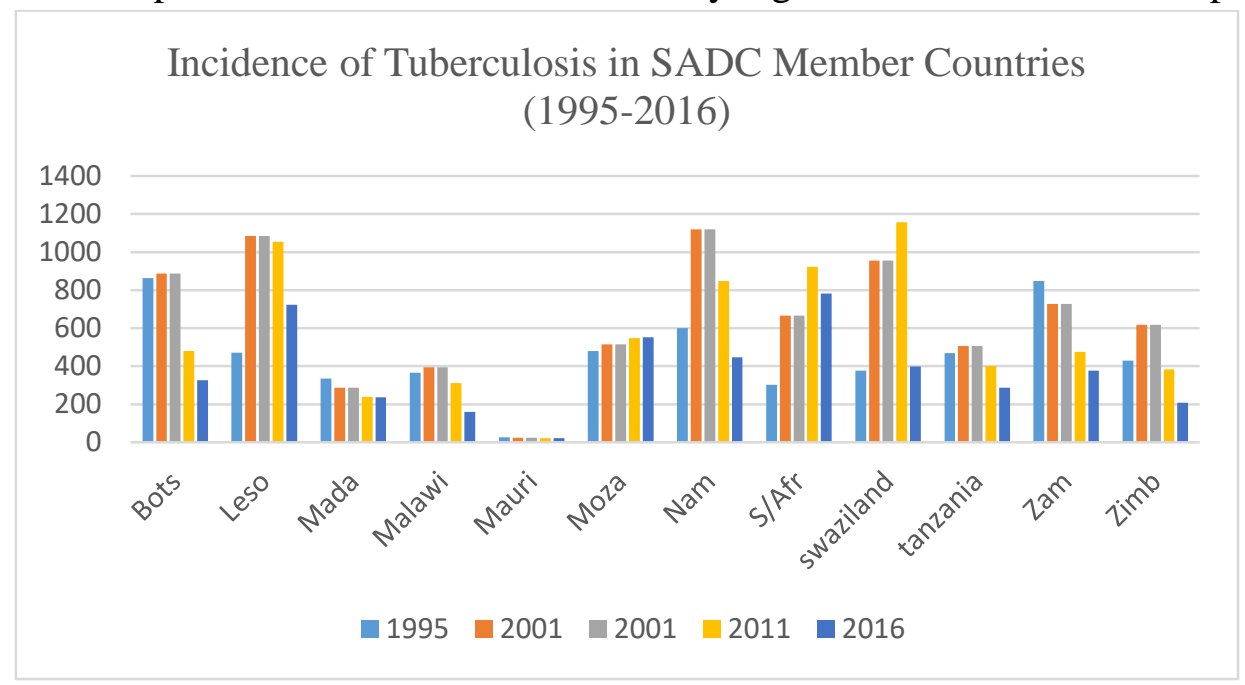

Figure 7: Incidence of Tuberculosis in SADC Member States Source: Author's Construct based on WDI Data 1995-2016 


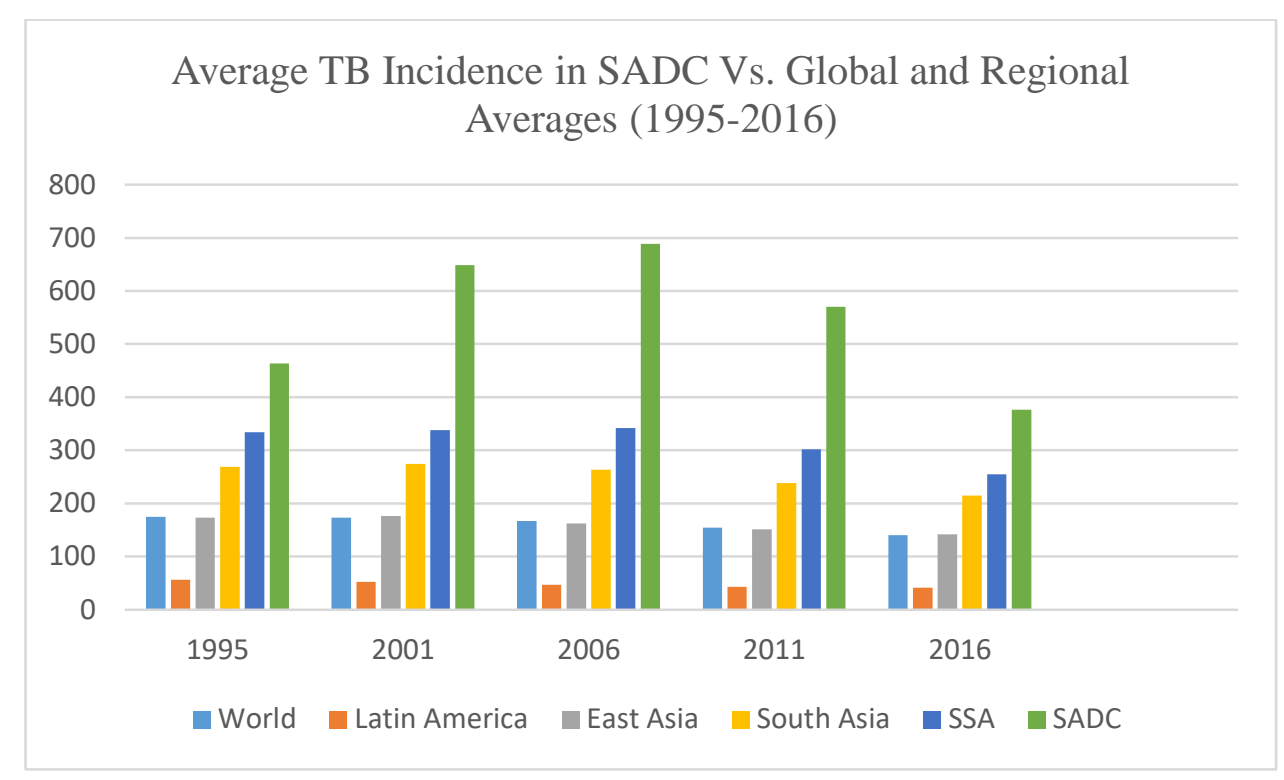

Figure 8: Average TB Incidence in SADC Bloc Vs. Global and Regional Averages Source: Author's Construct based on WDI Data 1995-2016

However, in the period between 2001 and 2006, there was a remarkable decline of $23 \%$ in Botswana; $20.7 \%$ in Zambia and 9.1\% in Zimbabwe, while it rose significantly in Lesotho, South Africa and Swaziland by $17.9 \%, 44.6 \%$ and $39.3 \%$ respectively. In the period between 2007 and 2011, TB incidence per 100,000 people declined in all the selected countries but Mozambique. The decline in that period was high in Botswana $(161 / 100,000)$, Lesotho (194/100,000), Swaziland (197/100,000) Tanzania (79/100,000) and Zimbabwe (140/100,000). Overall, due to the initial high burden of the disease, TB incidence remained relatively high in most of the selected SADC member countries despite the significant declines witnessed across the countries. Botswana had the highest decline in TB incidence per 100,000 people over the entire study period (537), followed by a decline of 471 in Zambia, 206 in Malawi, 182 in Tanzania and 155 in Namibia. Only in Lesotho, Mozambique, South Africa and Swaziland was the incidence higher in 2016 than it was in 1995. South Africa moved from being the second country with the least burden of tuberculosis $(302 / 100,000)$ in 1995 to occupy the position of the highest-burden of TB (781/100,000) in 2016, having the highest increase in the burden of TB (479) over the study period, while TB incidence per 100,000 similarly increased in Lesotho by 253, 72 in Mozambique and 21 in Swaziland.

\section{Conclusion}

In summary, the assessment of the burden of infectious diseases in the SSA region using the prevalence rates of HIV and incidence of TB revealed that the HIV prevalence rates and incidence of TB were uneven in the two selected trade blocs. The magnitude and the severity of the diseases varied. The burden of both diseases was higher for SADC and lesser for ECOWAS. The average prevalence rate of HIV in the SADC bloc over the study period was $600 \%$ of the prevalence rate in ECOWAS (SADC $=12.5 \%$, ECOWAS $=2.1 \%$ ). Likewise, in the same period, the average TB incidence per 100,000 people was 578.8 and 181.7 respectively in the SADC and ECOWAS blocs. 
Moreover, over the study period average burden of both diseases exceeded the global average in both blocs. Hence, the regional averages were relatively higher than the global averages and those of similar regions. While the global averages of HIV prevalence rate and incidence of TB per 100,000 people during the assessed period were $0.77 \%$ and 160.1 respectively, in SSA they were $5.16 \%$ and 314.6 respectively. In the same period, they were $0.45 \%$ and 46.1 in Latin America and $0.27 \%$ and 250.2 in South Asia, respectively. This corroborates the global consensus that the SSA region is a significant contributor to the global burden of infectious diseases (AVERT, 2018).

Overall, while the prevention and control of both diseases have remained top health priorities of global and regional development communities particularly as regards the subSaharan Africa region, there is still much to be done. Thus, there is a need to intensify the ongoing efforts at curbing the menace of both diseases. The awareness campaigns for the prevention and control of the diseases should be given wider coverage with more sensitization programs carried out in local languages for more understanding. Similarly, antiretroviral therapy (ART) should be accorded more attention in health policy formulation and budgeting by national governments and the development community to have wider coverage for the AIDS patient thus strengthening their quality of life.

\section{Conflicts of Interest:}

The authors declare no conflict of interest.

\section{Funding:}

This research was funded by African Economic Research Consortium (AERC), Grant number TT19005.

\section{References}

AVERT (2018). Annual report 2018-2019. Retrieved from:

https://www.avert.org/sites/default/files/Avert-annual-report-2018-19.pdf

Baingana, F. K., \& Bos, E. R. (2006). Changing patterns of disease and mortality in Sub-

Saharan Africa: an overview. Disease and Mortality in Sub-Saharan Africa. 2nd edition.

Basnyat, B., Caws, M., \& Udwadia, Z. (2018). Tuberculosis in South Asia: a tide in the affairs of men. Multidisciplinary respiratory medicine, 13(1), 1-8. https://doi.org/10.1186/s40248-018-0122-y

Centre for Disease Control and Prevention (CDC) (2017). World tuberculosis day - March 24, 2017. MMWR morbidity mortality weekly report (MMWR), 66:289. http://dx.doi.org/10.15585/mmwr.mm6611a1

Centre for Disease Control and Prevention (CDC) (2019). Tuberculosis. Retrieved from https://www.cdc.gov/globalhealth/newsroom/topics/tb/index.html,

Fenollar, F., \& Mediannikov, O. (2018). Emerging infectious diseases in Africa in the 21st century. New Microbes and New Infections, 26, S10-S18. https://doi.org/10.1016/j.nmni.2018.09.004 
Bloom, D., Kuhn, M., and Prettner, K. (2015). The Contribution of Female Health to Economic Development. National Bureau of Economic Research (NBER) Working Paper 21411.

Global Fund to Fight AIDS, Tuberculosis and Malaria (2014). Funding the global fight against HIV/AIDS, tuberculosis, and malaria. Geneva: The Partnership Profile.

Institute for Health Metrics and Evaluation (IHME) (2018). Findings from global burden of diseases study 2017. Seattle, WA: IHME, 2018.

Institute for Health Metrics and Evaluation (IHME) (2020). Global burden of diseases 2019. Seattle, WA: IHME, 2020. Retrieved from: http://www.healthdata.org/newsrelease/lancet-latest-global-disease-estimates-reveal-perfect-storm-rising-chronicdiseases-and

Vos, T., Lim, S. S., Abbafati, C., Abbas, K. M., Abbasi, M., Abbasifard, M., ... \& Bhutta, Z. A. (2020). Global burden of 369 diseases and injuries in 204 countries and territories, 1990-2019: a systematic analysis for the Global Burden of Disease Study 2019. The Lancet, 396(10258), 1204-1222. https://doi.org/10.1016/S0140-6736(20)30925-9

Lehoux, P., Pacifico Silva, H., Pozelli Sabio, R., \& Roncarolo, F. (2018). The unexplored contribution of responsible innovation in health to Sustainable Development Goals. Sustainability, 10(11), 4015. https://doi.org/10.3390/su10114015

Muula, A. (2008). HIV infection among young women in South Africa. Croatian Medical Journal, 49(3),423-435. https://doi.org/10.3325/cmj.2008.3.423

OECD/FAO (2016). Agriculture in Sub-Saharan Africa: Prospects and challenges for the next decade. OECD-FAO agricultural outlook 2016-2025. http://www.fao.org/3/aBO092E.pdf

Orach, C. (2009). Health Equity: Challenges in low-income countries. African Health Sciences, 9 (Suppl 2): 49-51.

Pelly, T., Moore, D., Gilman, R. and Evans, C. (2004). Recent tuberculosis advances in Latin America. Current Opinion in Infectious Diseases, 17(5):397-403.

UNAIDS (2018). Global HIV and AIDS statistics. Retrieved from: https://www.unaids.org/en/resources/fact-sheet

United Nations (2017). The Sustainable Development Goals Report. Retrieved from https://sdgactioncampaign.org/wpcontent/uploads/2017/07/TheSustainableDevelopmentGoalsReport2017.pdf,

Van de Maele, N., Evans, D., and Tan-Torres, T. (2013). Development assistance for health in Africa: Are we telling the right story? Bulletin of the World Health Organization, 91,483-490. http://dx.doi.org/10.2471/BLT.12.115410

Vermund, S., Sheldon, E., and Sidat, M. (2015). Southern Africa: The highest priority region

for HIV prevention and care intervention. Current HIV/AIDS Reports, 12(2), 191-195. https://doi.org/10.1007/s11904-015-0270-z

WHO (2017). Emergency, preparedness and response: Report on global surveillance of epidemic-prone infectious diseases - meningococcal disease. Retrieved from http://www.who.int/csr/resources/publications/meningitis/CSR_ISR_2000_1/en/,

WHO (2021). Coronavirus (COVID-19). WHO African region numbers at a glance. Retrieved from: https://www.afro.who.int/health-topics/coronavirus-covid-19 
World Bank (2013). The global burden of disease: Main findings for Sub-Saharan Africa.

Retrieved from https://www.worldbank.org/en/region/afr/publication/global-burden-

of-disease-findings-for-sub-saharan-africa

World Bank (2014). Poverty and Health. Retrieved from:

http://www.worldbank.org/en/topic/health/brief/poverty-health,

World Bank (2017). Sustainable Development Goals (SDG) Atlas: No Poverty. http://datatopics.worldbank.org/sdgatlas/SDG-01-no-poverty.html, 